the drum head into the middle ear, why the solution and not an ointment should be employed; but the ointment of the same strength is better adapted to the treatment of furuncles, for it will remain longer in contact with the parts. A powder which I employ in treating the respiratory passages may be used to cover furuncles, or to insufflate the middle ear when a perforation of the drum head is present. 'The powder consists of six (6) parts of cocaine hydrochlorate and ninety-four (94) parts of sugar of milk. This makes an impalpable powder which will readily pass with a column of air impelled through a perforation in the drum head. The instrument which I devised for insufflating cavities with powder is especially useful in this instance. It consists of a stout bottle three inches high and two inches in diameter, with a soft rubber stopier. There are two perforations extending vertically through the stopere, through which pass two vulcanite tubes. The latter pass downward through the stopper, but do not extend below its under surface. Alove the stoperer the tubes are hent in a curve so that their extremities point at right angles to their vertical portions. To one of these extremities is attached a rublere tube and bulb. The bull, contains a valve of soft rubber at either end, to prevent a regurgitation of the column of air sent into the bottle of powder, and a consecjutent dusting of the operator's clothing. By varying the force with which the bulb is compressed one may project a small or large quantity of the powcler into the car at pleasure.

There are other important effects of cocaine on mucous surfaces than that already mentioned. After it has been in contact with mucous membrane about ten minutes, the mucous tissue presents a pale and contracted appearance, even if it were previously red, swelled and painful, as it is in thrush, coryza and hay fever. This, together with the anesthetic effect, may be taken advantage of in catheterism of patients in whom the inferior meatus is constricted, and lined with a hypersensitive membrane. In those cases the powder is more conveniently applied than the solution, and the six per cent. powder is susceptible of more general application than any other. In mild cases of pain and hyperasthesia I have found the two per cent. preparation quite satisfactory.

Although the primary effect of cocaine on mucous tissue is to cause paleness and shrinking of the membrane, there is a secondary effect which I have observed repeatedly, but which I have never seen mentioned by any other writer. If the parts have been thoroughly anasthetized, and especially if they have been kejt in that condition for a number of hours by renewed applications of the remedy, there follows a considerable swelling of the membrane, which persists with more or less constancy for a day or two after the applications have been discontinued, and the subsequent hyperasthesia may be found to be alymented.

However, it must be conceded that cocaine has demonstrated itself to be the most important local anasthetic that medical science has yet discovered. But a few months old, in a therapentic sense, its brilliancy of achievement has flashed like a meteor over the whole medical world. So deep an impression has it made on suffering humanity that it ${ }_{j}$ has rapidly passed beyond the conservative control of professional men. The laity grasps at anything that promises to be a boon-a panacea for all aches and pains. An indiscriminate use results-an actual abuse of a remedy as potent for evil as it is powerful for good. Already the cocaine habit has supplanted the morphine, alcohol or chloral habit. A step) in the right direction has been taken by the profession of New York, by the preparation of a bill for the Legislature, to place cocaine on the list of poisons to be sold only on physicians' prescriptions.

Cocaine poisoning has repeatedly occurred, and in the midst of our own ranks, impaired health and temporary insanity are attributed to the excessive use of this drug. So, while lauding its merits, let us manifest a just appreciation of its dangers, and erect lighthouses of caution with the victims who have fallen prey to its direful power. But the history of medicine is like the history of men. The greater the man, the grosser the abuse. 'The better the drug, the worse is its misistse. A note of timely warning should be sommed, and the daty of the conscientions physician done, for although one cannot be the keeper of his pattents' wills, he should be a guardian of their health and morals.

No. ${ }_{39}$ Center Ave, Chicaso.

\section{THE FLAP EXTRACTION OF SENILE CATARACT.}

BY J. W. THOMPSON, M.D., or ST. I'AUL, MUNNESOTA.

Of all the methods of dealing with senile cataract that have at various times been detailed and advocated by different authors, the upper flap with an iridectomy has been.attended with more uniform and favorable results than any other. The flap extraction was first practiced without the removal of a segment of the iris. The results thus obtained were superior to those by any of the other methods that had been previously practiced. Statistics show that about ten per cent. of the cases thus treated were lost. Mooren, of Duisseldorf, in 1862 proposed the following method: He first did a very free iridectomy, removing a large segment of the iris. He then allowed the eye fully to recover, waiting perhaps three or six months as the case might require, when he made the ordinary flap upwards and extracted the lens. This method has to-day many advocates, and its advocacy is founded upon sound principles. Small insults can be tolerated better than great ones. It divides the operation into two equal parts, and likewise divides the danger to the organ. 'The flap extraction is not, however, without its dangers.

There may be diffused or defined suppuration of the cornea, or iritis, and in extreme cases of danger there may be not only iritis and suppuration of the cornea in conjunction, but every structure of the organ may be seized with an active form of inflammation which, with the unfavorable surroundings, would terminate in suppuration and its entire destruction. Iridectomy is powerless to protect against the calam- 
ity of diffused suppuration of the cornea, while it chamber partially or perhaps wholly filled with blood might exercise a good influence in the event of a from a bleeding iris. 2. The dimirished tension threatened defined inflammation. It does, however, lessens the chances of rupturing the posterior capgive a high degree of immunity from iritis. In every sule, which might allow the vitreous to come fortlap extraction accompanied with an iridectomy at wards into the chambers, a circumstance highly to be the same time, iritis is one of the chief dangers to be deprecated.

anticipated. It is no exaggeration to say that nine- The methorl of making the flap has been regulated tenths of the failures that occur in flap extraction by laws which give the greatest possible space for when the iridectomy is done at the same time, have th their origin in iritis.

When the iris is wounded and left without its natural lens support it is very much more susceptible to acute inflammatory action. Hence, when the iridectomy is done as a preliminary step the iris is left with its natural lens support and is placed under the most favorable circumstances for recovery, and thus al the danger from iritis is almost if not quite removed when the subsequent flap is made for the removal of the lens. If the final operation be dextronsly done the iris is but little disturbed. The upward tlap with the iridectomy, of course, in the same direction, is preferable to the downward direction for two reasons: 1. 'The upper lid furnishes an excellent sup)port to the flap and holds the corneal edges in close coaptation, a circumstance both essential and desirable for a rapid union of the parts. 2. The artificial pupil is covered by the upper lid, which not only obscures the deformity but prevents that disagreeable dazzling, an unavoidable concomitant when the pupil is made in any other direction. This method, however, of treating senile cataract has been objected to by many on the ground that the patient is subjected to the anxiety of two separate and distinct operations. This objection is, I think, in a very great measure overcome since the introduction of the use of cocaine as an anesthetic in ophthalmic surgery.

When this agent is properly employed both the operations are rendered almost or quite painless. By way of illistration I had occasion to do an iridectomy a short time since, and after completing the operation the patient in a very complacent manner asked me if $I$ would soon be ready to begin. When the first operation has thus been demonstrated to the patient to be painless while consciousness is undisturbed, the subsequent one is in a very great de-! the gree robbed of its anxiety. But it has been urged by some as a serious objection against the use of cocaine in the cataract operation that it diminishes the tension of the globe, thereby increasing the difficulty of the operation. 'This is another hair-splitting objection.! Can any one tell why it should lessen the tension any more thin atropine? Is it a fact that it does? It is a well recognized practice and I think a very good one, to drop into the eye a solution of atropine of sufficient strength to procure as wide a dilatation of the pupil as possible before operating. I have used both hundreds of times and have never been able to discover that the one diminished the tension any more than the other. Admitting for the sake of argument that cocaine is the more relaxing of the two, I think that the slight inconvenience to the operator is compensated in a twofold ratio: I. It renders the operation almost or quite bloodless, and thus prevents that occasional and disagreeable occurrence, $a$ is a slight difference in favor of the sclerotic, it 
would be unquestionably more than overbalanced by going as near the ciliary region as is necessary to make the flap wholly in this tissue. This is the dangerous region of the eye, and the wider one steers of it in any operation the less is the result jeopardized. The sclero-corneal flap is, in a diminished degree, however, open to the same objections. 'l'he reason, therefore, for making it wholly in the cornea is twofold: I. It is farther removed from the ciliary region, and 2. 'I"se experience of such men as the late $\mathrm{Mr}$. Critchett, of Jondon, confirms the assertion that this tissue unites more readily than the sclerotic.

There are some objective symptoms that are valuable in giving a prognosis as to the result to be obtained by the flap extraction. The first of these is the condition of the pupil: whether it be active or sluggish, whether it respond promptly to the influence of light and shade, and atropine. The latter condition is the more favorable one, from the fact that the stiff, thick, sluggish iris is predisposed 10 iritis. 'The muscle is partially deprived of its animal matter, its fibres are inliltrated with disorganized material which deprives it of its normal elasticity and power to resist inflammatory action. Its vitality is lowered, and consequently its power to resist mechanical injury diminished. 'Therefore an active pupil can in truth be sald to be a tiavorable prognostic symprom. Again, the flap operation should not be attempted when there is the stightest evidence of conjunctivitis. Cure this first. Neither the patient nor the physician can afford to disregard this one, little, important point. The drainage apparatus of the eye should also be carefully inspected.

When the extraction of the lens is completed, a collapse of the capsule is another favorable indication. The reason for this is twofold. I. It is an evidence that the posterior capsule is intact, or at least that the vitreous has not been disturbed; and 2. 'That the cornea is in a healthy condition, as evidenced by its pliability. These are some of the considerations that should govern one in giving an opinion as to the probable results of a flap extraction.

Again, an extraction should not be done when there is any prevailing epidemic, such as cholera or any of the exanthemata. The depressing influences of these upon the mind of the patient disarms, as it were, the physical forces, and thus, in the unguarded moments of nature, golden opportunities are thrown away and forever lost. It is so unlike many other operations, since the slightest error may turn the tide of success and leave the patient in total darkness.

'The general condition of the patient's health should a]so receive the most careful attention. In short, the more carefully every detail, be it ever so small, is considered, the greater will be the chances of success. As the whole is composed of parts, so little ills combine to establish a morbid condition which may defeat the desired result. The experience of the past few years has also wrought some very valuable changes in the after-treatment of flap extraction. When the edges of the flap are brought into close contact with each other and all coagula carefully removed, the present practice is to close the eye, cover it with a circular piece of soft linen, and then fill up the orbital cavity with little pieces of carbolized cotton, eyually distributed. Before applying the bandage, place a few pieces of the cotton around the orbit in such a manner as to prevent too much pressure directly upon the eyeball. I prefer a flannel roller, which should be passed around the head three or four times in such a manner as to cover the eye and give an equal support to the entire surface of the globe.

'The other eye should be covered as well, in order to insure perfect rest to its fellow. The bandage and cotton should be changerl every twenty-four hours. If all goes well, this is the only dressing that will be required. 'The old practice of applying cold water dressing has been entirely discarded. It washes away the corneal cementum and embarrasses the reparative process. There are numerous emergencies that may arise, but to detail them here, with the various methods of treatment, would extend far beyond the limits assigned to this paper. Before dismissing the subject, however, permit me to ask of my readers for any innovations on the established order of things contained herein, a resistance that loves to be reasonable rather than energetic.

309 Wabasha St., St. Paul, Minn.

\section{SOME PECULIAR CASES OF EPIDEMIC FEVER OCCURRING IN TOULON, ILLINOIS.' \\ I3Y W. T. HALL, M.D., or roulon, Il.sinols.}

The purpose of this paper is to give a history of a peculiar epidemic which recently occurred in Toulon, Stark Co., Illinois. 'This history may, however, be prefaced by saying that 'Toulon is well watered, very few of the wells being influenced by surface water, and no cases of the epidemic occurred in the part of the town where the wells are so influenced. The natural drainage is far superior to that of most towns, and the sewerage has been carefully, scientifically and methodically cared for.

Having lived in the town for forty years, having known all the epidemics of the town, and having only known of one family before in which typhoid fever originated and went through the whole family, I was at a loss to account for this abrupt appearance, and persistent protraction. The number of cases thus far have been twenty-six, the ages ranging from I I to 67 years. These have all been typical, well-marked cases, though many others in the different families in which the disease has appeared have had some of the premonitory symptoms, but no further development.

Nineteen of these cases came under my care, and in speaking of this epidemic I will only describe those under my own personal observation. The first patient was taken sick July 27, I 885 , and they have continued to make their appearance up to the present writing (November 9). 'The premonitory symptoms for the first ten days are those of typhoid fever, with the exception of more lassitude and more catarrhal trouble. On the eleventh day in thirteen of these cases, and in the remainder on the twelfth day, de-

1 Read before the Military Tract Medical Socicty, on November 10, 1885 